\title{
RESEARCH
}

Open Access

\section{Public knowledge about Alzheimer disease in Mecca Region, Kingdom of Saudi Arabia: a cross-sectional study}

\author{
Faisal Salem Alhumaidi ${ }^{1 *}$ (D), Muhammad Irfanullah Siddiqui ${ }^{2}$, Abdulaziz Fahad Altowairqi ${ }^{1}$, \\ Hattan Hassan Alshawkani ${ }^{1}$, Bashar Omar Babkour ${ }^{1}$ and Fahad Khalid Alaugla'
}

\begin{abstract}
Background: Raising the general population knowledge of Alzheimer's disease is crucial for optimizing care and ultimately enhancing the quality of life of people diagnosed and their caregivers.

Aim: To assess knowledge among the general population in Makkah Region about symptoms, diagnosis, causes, course, life impact, care giving, and management of Alzheimer disease.

Material and methods: A descriptive cross-sectional study was conducted during July to August 2018 in three main cities of Makkah Region, i.e., Makkah, Jeddah, and Taif, Saudi Arabia. Two to three mosques and/or malls were selected randomly from a list of all mosques and malls in each city, and then every fifth subject was selected using a systematic random technique, entering the mall or getting out from the mosques. Both genders, aged 18 years or more and able to understand Arabic were included. Valid and reliable Alzheimer's Disease Knowledge Scale (ADKS) was used to assess knowledge about the diseases, in addition to socio-demographic characteristics of the participants.
\end{abstract}

Results: The study included 862 adult participants. Their age ranged between 18 and 65 years with a mean \pm standard deviation (SD) of $31.2 \pm 10.3$ years. History of having a relative with Alzheimer's disease was mentioned by $20.8 \%$ of the participants. Overall, the percentage of total Alzheimer's disease knowledge score ranged between 26.7 and $100 \%$ with a mean of $58.5 \%$, median of $60 \%$, mode of $56.7 \%$, and standard deviation of $\pm 11.5 \%$. There was a significant positive correlation between participant's age and their knowledge regarding Alzheimer's disease (Spearman's correlation coefficient " $r$ " $=0.099, p=0.004$ ). The highest known subscale of Alzheimer's disease was assessment (mean percentage was 62.21\%), followed by treatment (62.09), care giving (61.83\%) and course of the disease (60.99\%) whereas the lowest known subscale was symptoms (53.25\%). Participants who reported a history of having a relative with Alzheimer's disease were more knowledgeable regarding symptoms than those who did not had such history (mean ranks were 470.48 and 421.28 , respectively), $p=0.014$.

Conclusion: Knowledge of the general population in Makkah Region is deficient, particularly regarding symptoms, risk factors and life impacts. Therefore, health education campaigns are required for general public in this regards.

Keywords: Alzheimer's disease, Knowledge, Risk factors, Alzheimer's Disease Knowledge Scale, Saudi Arabia

\footnotetext{
* Correspondence: faisal1546-2013@hotmail.com

'Umm Al-Qura University College of Medicine, Mecca, Saudi Arabia

Full list of author information is available at the end of the article
}

\section{Springer Open}

(c) The Author(s). 2020 Open Access This article is licensed under a Creative Commons Attribution 4.0 International License, which permits use, sharing, adaptation, distribution and reproduction in any medium or format, as long as you give appropriate credit to the original author(s) and the source, provide a link to the Creative Commons licence, and indicate if changes were made. The images or other third party material in this article are included in the article's Creative Commons licence, unless indicated otherwise in a credit line to the material. If material is not included in the article's Creative Commons licence and your intended use is not permitted by statutory regulation or exceeds the permitted use, you will need to obtain permission directly from the copyright holder. To view a copy of this licence, visit http://creativecommons.org/licenses/by/4.0/. 


\section{Introduction}

Alzheimer's disease (AD) is an irreversible progressive brain disease that gradually and slowly destroys memory and rational thinking processes and skills and eventually it affects the ability to perform the simplest tasks. Usually, the majority of the inflicted cases start to develop Alzheimer's signs and symptoms after the age of 60 . Nearly $3 \%$ of men and women ages 65-74 and almost half of those aged 85 and above usually have the disease with an average age at diagnosis of about 80 years. AD is the most underlying cause of dementia among older people that is characterized by the loss of cognitive functioning, thinking, remembering, reasoning, and behavioral abilities, to the degree that it interferes with a person's daily life and basic activities [1]. According to the DSM3, the person of $\mathrm{AD}$ "must have the criteria for major or mild neurocognitive disorder in addition to insidious onset and gradual progression of impairment in one or more cognitive domains (for major neurocognitive disorder, at least two domains must be impaired)" [2].

The Saudi Alzheimer's Disease Association reported that Alzheimer's disease accounts for 50 to $80 \%$ of dementia cases worldwide and the greatest known risk factor is increasing age of 65 and older. There are no official statistics on the prevalence of Alzheimer's disease in the Saudi Arabia, but experts estimate that there are at least 50 thousand patients in the Kingdom; most of them are women and there are chances of getting the disease to double each 5 years [3]. Studies in Arab countries revealed a prevalence ranging from 1.1 to $2.3 \%$ among people aged 50 years and older and from 13.5 to $18.5 \%$ among those aged 80 years and above [4]. The prevalence in the USA was $1.6 \%$ among people in the age group 65-74 years and $19 \%$ in the age group 75-84 years and reached up to $42 \%$ among those aged 85 years old and above [5].

Patients with Alzheimer's disease are characteristically exhibit and show symptoms of impaired memory and decision-making abilities, as well as other problems with their behavior and verbal abilities $[6,7]$.

As these caregivers witness the person with Alzheimer disease "die twice," first in mind and then a few years later in body, they make day-to-day and often ethically charged decisions for the patient as they themselves experience notable morbidity, especially depression [8]. Other problems they may face include fall down and losses of dignity and respect, as well as abuse, neglect, and exploitation [9].

Matters of daily living become challenging and difficult when Alzheimer's disease influences the patients their families and caregivers. During the progress of the disease, the caregivers, in addition to their own personal business and needs, are charged with more responsibilities, duties including seeking, dealing with healthcare providers, negotiating medications, monitoring patient's behavior, and attending to the daily needs and requirements of the patient $[9,10]$.

Raising public knowledge of dementia is crucial for optimizing care and ultimately enhancing the quality of life of people diagnosed and their caregivers [11]. Increasing the knowledge levels of the general population will also help to tackle the stigma of dementia and open up a betterinformed debate about the needs of those affected.

The first step toward improving dementia knowledge of population is to assess their current level of dementia knowledge using a reliable tool that will identify knowledge gaps. Additionally as the problem is considerable in our country as a result of aging induced by improvement of care, although there is no epidemiologic evidence, it could have socioeconomic drawbacks and hence tracing community knowledge about the disease will help in prevention and treatment, so in this study, knowledge was measured among the population in Mecca Region about symptoms, diagnosis, causes, course, life impact, care giving, and management of Alzheimer disease.

\section{Population and methods}

It is a descriptive cross-sectional study conducted during July to August 2018 in three main cities of Makkah Region, i.e., Makkah, Jeddah, and Taif, Saudi Arabia. Two mosques and one mall (because the authority prohibited us from including people from the other mall) were selected randomly from a list of the biggest in Makkah city, whereas two mosque and three malls were selected from Jeddah city and two mosques and two malls from Taif city and then every fifth subject was selected using a systematic random technique, entering the mall or getting out from the mosques. Both genders, aged 18 years or more and able to understand Arabic were included. Those aged over 65 years were excluded.

The data collection took about 2 months after getting the approval from the ethical committee of Umm Al Qura University. The purpose of the study was explained briefly and those who agreed and met the study criteria were invited to answer the question. One hundred and forty two persons refused to participate, mostly because they were busy and had no time. Those who refused were replaced immediately by the next one who agreed to participate. Valid and reliable Alzheimer's Disease Knowledge Scale (ADKS) was used to assess knowledge about the diseases [9], in addition to socio-demographic characteristics of the participants. The ADKS is the only tool that can be used to assess knowledge about Alzheimer disease in general population; however, it includes some relatively easy items for those with some knowledge on the disease. It has an acceptable reliability and validity and reliability values [12]. 
The total sample size was calculated using epi info software version 3.01. Based on frequency of knowledge of Alzheimer's disease and as there was no reliable data, $50 \%$ prevalence was utilized and design effect of two to calculate sample size, the confidence interval was set at $95 \%$, and level of significance at $5 \%$. Hence, the calculated sample size was 768 . We added 77 more anticipating a non-response rate of $10 \%$. Hence, a total sample size estimated was 845 .

Surveys are completely anonymous and confidential. No names or any identifying information is required. In addition, the surveys were not distributed before getting the ethical approval from Umm Al-Qura University IRB. The participation in this study was voluntary, the collected information were kept in sealed envelopes by the participants before returning it to the investigators.

\section{Statistical analysis}

Data entry and statistical analysis were performed utilizing the Statistical Package for Social Sciences (SPSS) software, version 25. Descriptive statistics was done using frequency and percentages for categorical variables and mean and standard deviation for continuous variables. Since the total of subscales knowledge scores were abnormally distributed as evidenced by significant Shapiro-Wilk test, they were described in the form of median, inter-quartile range, and mean ranks. Nonparametric statistical tests were used in comparisons. Mann-Whitney was applied to test for difference between two different groups and Kruskal-Wallis was applied to test for the difference between more than two groups. Statistical significance was determined at level of $p<0.05$.

\section{Results}

The study included 862 adult participants. Their age ranged between 18 and 65 years with a mean \pm standard
Table 1 Personal characteristics of the participants $(n=862)$

\begin{tabular}{lll}
\hline & Frequency & Percentage \\
\hline $\begin{array}{lll}\text { Gender } \\
\text { Male }\end{array}$ & 383 & 44.4 \\
Female & 479 & 55.6 \\
Nationality & 743 & \\
Saudi & 119 & 86.2 \\
Non-Saudi & & 13.8 \\
Years of education & 63 & \\
$\quad \leq 9$ & 240 & 7.3 \\
10-12 & 486 & 27.8 \\
13-16 & 73 & 56.4 \\
$\quad>16$ & & 8.5 \\
City & 249 & 28.9 \\
Makkah & 305 & 35.4 \\
Jeddah & 308 & 35.7 \\
Taif & &
\end{tabular}

deviation (SD) of $31.2 \pm 10.3$ years. Table 1 summarizes the remaining demographic characteristics of the participants. More than half of them (55.6\%) were females and had between 13 and 16 years of education (56.4\%). Majority $(86.2 \%)$ were Saudis. Less than one third were recruited from Makkah as we are prohibited from including one another mall while $71 \%$ were from Jeddah and Taif.

History of having a relative with Alzheimer's disease was mentioned by $20.8 \%$ of the participants as demonstrated in Fig. 1.

Table 2 shows that majority of the participants could recognize correctly that eventually, a person with Alzheimer's disease will need $24 \mathrm{~h}$ supervision (83.3\%), people with Alzheimer's disease are particularly prone to

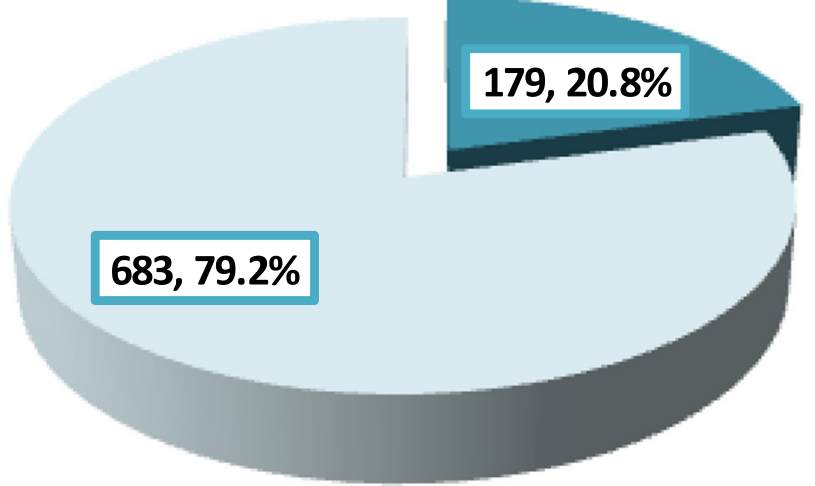

Yes

No

Fig. 1 History of having a relative with Alzheimer's disease among the participants 
Table 2 Response of the participants to Alzheimer's disease knowledge statements

\begin{tabular}{|c|c|c|}
\hline & \multicolumn{2}{|c|}{$\begin{array}{l}\text { Right } \\
\text { answer }\end{array}$} \\
\hline & No. & $\%$ \\
\hline People with Alzheimer's disease are particularly prone to depression. (True) & 691 & 80.2 \\
\hline It has been scientifically proven that mental exercise can prevent a person from getting Alzheimer's disease. (False) & 558 & 64.7 \\
\hline After symptoms of Alzheimer's disease appear, the average life expectancy is 6 to 12 years. (True) & 365 & 42.3 \\
\hline $\begin{array}{l}\text { When a person with Alzheimer's disease becomes agitated, a medical examination might reveal other health problems that caused the } \\
\text { agitation. (True) }\end{array}$ & 610 & 70.8 \\
\hline People with Alzheimer's disease do best with simple, instructions given one step at a time. (True) & 637 & 73.9 \\
\hline When people with Alzheimer's disease begin to have difficulty taking care of themselves, caregivers should take over right away. (False) & 540 & 62.6 \\
\hline $\begin{array}{l}\text { If a person with Alzheimer's disease becomes alert and agitated at night, a good strategy is to try to make sure that the person gets } \\
\text { plenty of physical activity during the day. (True) }\end{array}$ & 629 & 73.0 \\
\hline In rare cases, people have recovered from Alzheimer's disease. (False) & 428 & 49.7 \\
\hline People whose Alzheimer's disease is not yet severe can benefit from psychotherapy for depression and anxiety. (True) & 649 & 75.3 \\
\hline If trouble with memory and confused thinking appears suddenly, it is likely due to Alzheimer's disease. (False) & 377 & 43.7 \\
\hline Most people with Alzheimer's disease live in nursing homes. (False) & 352 & 40.8 \\
\hline Poor nutrition can make the symptoms of Alzheimer's disease worse. (True) & 633 & 73.4 \\
\hline People in their 30s can have Alzheimer's disease. (True) & 490 & 56.8 \\
\hline A person with Alzheimer's disease becomes increasingly likely to fall down as the disease gets worse. (True) & 592 & 68.7 \\
\hline $\begin{array}{l}\text { When people with Alzheimer's disease repeat the same question or story several times, it is helpful to remind them that they are } \\
\text { repeating themselves. (False) }\end{array}$ & 402 & 46.6 \\
\hline Once people have Alzheimer's disease, they are no longer capable of making informed decisions about their own care. (False) & 457 & 53.0 \\
\hline Eventually, a person with Alzheimer's disease will need 24-h supervision. (True) & 718 & 83.3 \\
\hline Having high cholesterol may increase a person's risk of developing Alzheimer's disease. (True) & 372 & 43.2 \\
\hline Tremor or shaking of the hands or arms is a common symptom in people with Alzheimer's disease. (False) & 418 & 48.5 \\
\hline Symptoms of severe depression can be mistaken for symptoms of Alzheimer's disease. (True) & 473 & 54.9 \\
\hline Alzheimer's disease is one type of dementia. (True) & 685 & 79.5 \\
\hline Trouble handling money or paying bills is a common early symptom of Alzheimer's disease. (True) & 482 & 55.9 \\
\hline One symptom that can occur with Alzheimer's disease is believing that other people are stealing one's things. (True) & 528 & 61.3 \\
\hline When a person has Alzheimer's disease, using reminder notes is a crutch that can contribute to decline. (False) & 405 & 47.0 \\
\hline Prescription drugs that prevent Alzheimer's disease are available. (False) & 475 & 55.1 \\
\hline Having high blood pressure may increase a person's risk of developing Alzheimer's disease. (True) & 405 & 47.0 \\
\hline Genes can only partially account for the development of Alzheimer's disease. (True) & 506 & 58.7 \\
\hline It is safe for people with Alzheimer's disease to drive, as long as they have a companion in the car at all times. (False) & 384 & 44.5 \\
\hline Alzheimer's disease cannot be cured. (True) & 454 & 52.7 \\
\hline Most people with Alzheimer's disease remember recent events better than things that happened in the past. (False) & 408 & 47.3 \\
\hline
\end{tabular}

depression (80.2\%), Alzheimer's disease is one type of dementia (79.5\%), people whose Alzheimer's disease is not yet severe can benefit from psychotherapy for depression and anxiety (73.5\%), and people with Alzheimer's disease do best with simple, instructions giving one step at a time (73.9\%). On the other hand, only $44.5 \%$ of them knew that it is not safe for people with Alzheimer's disease to drive, as long as they have a companion in the car at all times, $43.2 \%$ could recognize that having high cholesterol may increase a person's risk of developing Alzheimer's disease, having high cholesterol may increase a person's risk of developing Alzheimer's disease (43.2\%), after symptoms of Alzheimer's disease appear, the average life expectancy is 6 to 12 years (42.3\%), and most people with Alzheimer's disease do not live in nursing homes (40.8\%).

Overall, the percentage of total Alzheimer's disease knowledge score ranged between 26.7 and $100 \%$ with a mean of $58.5 \%$, median of $60 \%$, mode of $56.7 \%$, and standard deviation of $\pm 11.5 \%$. It was abnormally 
distributed as evident by significant Shapiro-Wilk test (0.990, $p<0.001$; Fig. 2).

From Table 3, it is shown that none of the studied factors (gender, nationality, years of education, city, and having a relative with Alzheimer's disease) was significantly associated with the knowledge level regarding Alzheimer's disease. However, there was some border line association observed between knowledge level and relative with Alzheimer disease, though it did not reach to significant level.

From Fig. 3, it is realized that there was a significant positive correlation between participant's age and their knowledge regarding Alzheimer's disease (Spearman's correlation coefficient " $r$ " $=0.099, p=0.004$ ).

From Fig. 4, it is obvious that, the highest known subscale of Alzheimer's disease was assessment (mean percentage was $62.21 \%$ ), followed by treatment (62.09), care giving (61.83\%), and course of the disease (60.99\%), whereas the lowest known subscale was symptoms (53.25\%).

As demonstrated from Table 4. There was no gender difference regarding knowledge of different aspects of Alzheimer's disease (life impact, risk factors, symptoms, treatment, assessment, care giving, and course of the disease).
As realized from Table 5, there was no nationality difference regarding knowledge of different aspects of Alzheimer's disease (life impact, risk factors, symptoms, treatment, assessment, care giving, and course of the disease).

As seen in Table 6, participants who had more than 16 years of education expressed the highest level of knowledge regarding course of the disease (mean rank was 452.55) whereas participants with 9 years of education or less expressed the lowest level of knowledge (mean rank was 387.97), $p=0.035$. There was no difference regarding knowledge of other aspects of Alzheimer's disease (life impact, risk factors, symptoms, treatment, assessment, and care giving) according to participant's years of education.

Participants from Taif were more knowledgeable regarding life impact and treatment compared to those from Jeddah and Makkah, whereas participants from Jeddah were more knowledgeable regarding risk factors, while those from Makkah were more knowledgeable regarding caregiving. There was no difference between participants from the three cities regarding symptoms, assessment, and course of the disease (Table 7)

As evident from Table 8, participants who reported a history of having a relative with Alzheimer's disease were

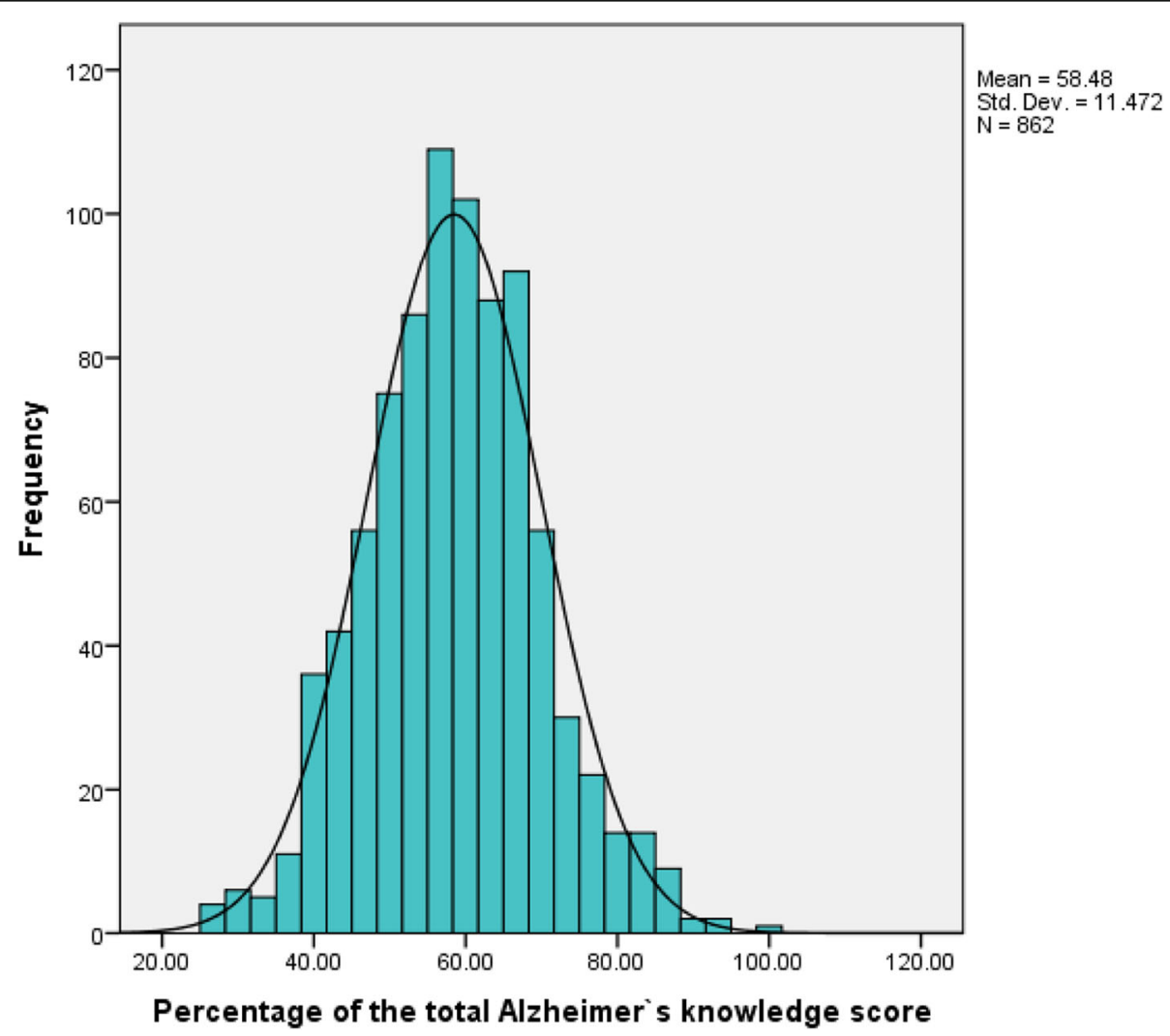

Fig. 2 Distribution of the percentage of the total Alzheimer's knowledge score among the participants 
Table 3 Factors associated with percentage of the total Alzheimer's knowledge score among the participants

\begin{tabular}{|c|c|c|c|c|}
\hline & \multicolumn{3}{|c|}{ Percentage of the total Alzheimer's knowledge score } & \multirow{2}{*}{$\begin{array}{l}P \\
\text { value }\end{array}$} \\
\hline & Median & IQR & Mean rank & \\
\hline \multicolumn{5}{|l|}{ Gender } \\
\hline Male & 56.67 & $50-66.67$ & 429.14 & \multirow[t]{2}{*}{$0.803^{*}$} \\
\hline Female & 60 & $50-66.67$ & 433.39 & \\
\hline \multicolumn{5}{|l|}{ Nationality } \\
\hline Saudi & 60 & $50-66.67$ & 433.23 & \multirow[t]{2}{*}{$0.609^{*}$} \\
\hline Non-Saudi & 56.67 & $50-66.67$ & 420.69 & \\
\hline \multicolumn{5}{|l|}{ Educational level } \\
\hline Below high school & 60 & $53.33-66.67$ & 461.64 & \multirow[t]{4}{*}{$0.582^{* *}$} \\
\hline High school & 56.67 & 50-66.6750- & 425.43 & \\
\hline University & 56.67 & 66.6753.33- & 426.91 & \\
\hline Postgraduate & 60 & 66.67 & 456.03 & \\
\hline \multicolumn{5}{|l|}{ City } \\
\hline Makkah & 60 & $51.67-66.67$ & 458.43 & \multirow[t]{3}{*}{$0.096^{* *}$} \\
\hline Jeddah & 56.67 & $50-66.67$ & 428.10 & \\
\hline Taif & 56.67 & $50-63.33$ & $413 . .09$ & \\
\hline \multicolumn{5}{|c|}{ Having a relative with Alzheimer's disease } \\
\hline Yes & 60 & $53.33-66.67$ & 423.73 & \multirow[t]{2}{*}{$0.072^{*}$} \\
\hline No & 56.67 & $50-66.67$ & 461.14 & \\
\hline
\end{tabular}

*Mann-Whitney test

**Kruskal-Wallis test

more knowledgeable regarding symptoms than those who did not have such history (mean ranks were 470.48 and 421.28 , respectively), $p=0.014$. There was no significant difference between both groups regarding other subscales.

\section{Discussion}

Although changes of some lifestyles could impact positively the human health, the general population appears to be unaware of this fact and, consequently, does not adhere to these health habits that could reduce the risk of developing Alzheimer's disease [13]. This study was conducted with primary aim to explore the knowledge level about symptoms, diagnosis, causes, course, life impact, caregiving, and management of Alzheimer's disease among general population in three main cities of Western Saudi Arabia.

The present study revealed that the overall percentage of total Alzheimer's disease knowledge score ranged between 26.7 and $100 \%$ with a mean of $58.5 \%$, median of $60 \%$, mode of $56.7 \%$ which indicate moderate level of knowledge. Quite similar findings were observed among general population in Brazil [14]. However, expectedly higher figures were reported in studies carried out among pharmacists in Malaysia [15], healthcare professionals in Australia [16], and psychologists in Norway
[17]. These results could be attributed to the fact that general population usually lack open access to high quality information, contrary to those working in medical field. Cahill et al. carried out systematic review included 40 studies from different developed and developing nations that evaluated the knowledge about Alzheimer's disease in the population and concluded that about half of these studies revealed a limited knowledge about Alzheimer's disease in the general population with a common concept that $\mathrm{AD}$ is part of aging [18].

In the current study, gender, nationality, years of education, city, and having a relative with Alzheimer's disease were not significantly associated with the knowledge level regarding Alzheimer's disease as a total. However, taking the subscale of knowledge into consideration, participants with higher years of education were more knowledgeable regarding course of the disease and this is quite expected. Also, it was expected to find participants who had relatives with Alzheimer's disease more knowledgeable about symptoms of the disease as they are dealing with such patients. Regarding participants' age, contrary to what has been reported in a previous systematic review [18], older participants were more knowledgeable. This could be explained by limiting the inclusion in the present study to those aged 65 years or below. 


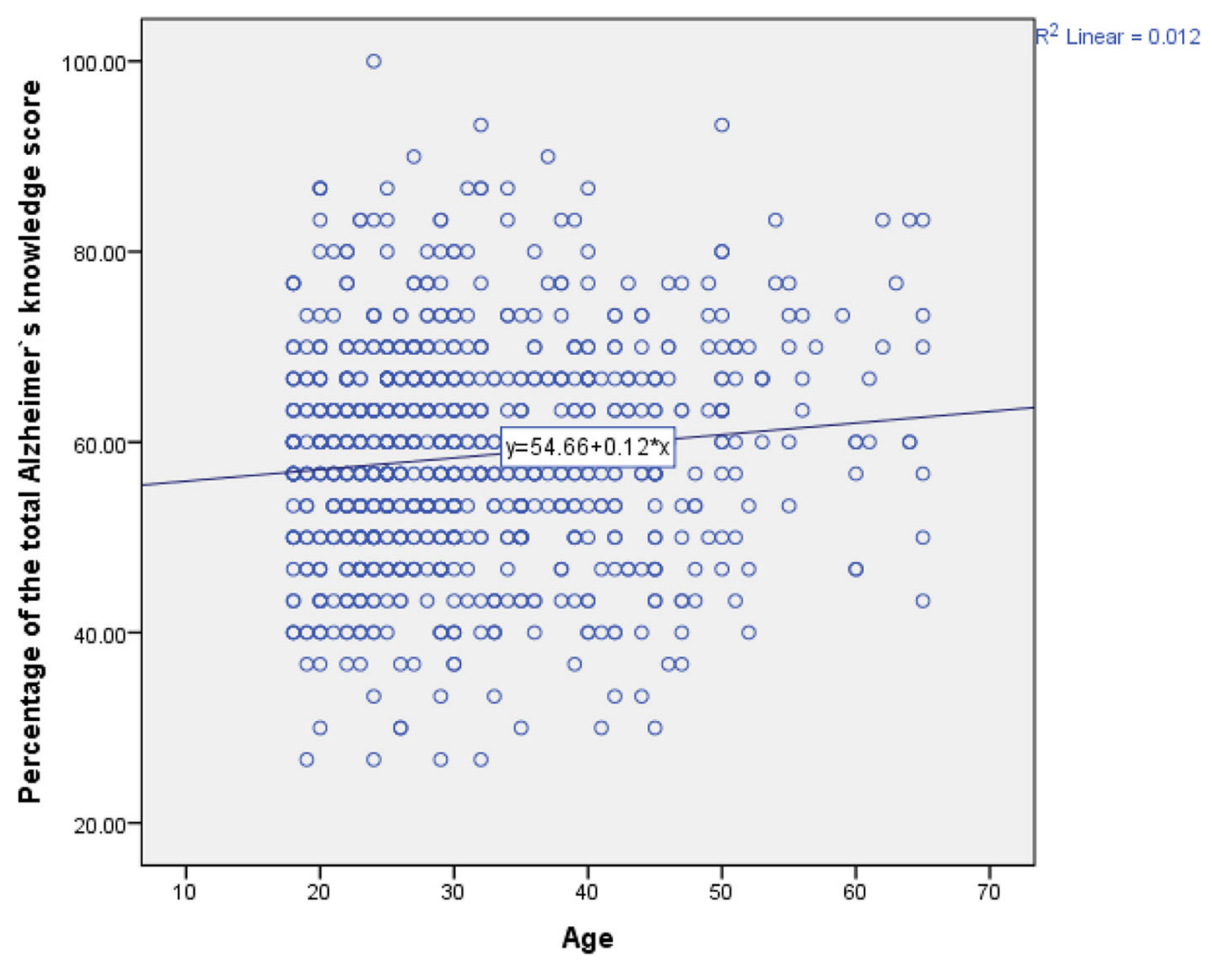

Fig. 3 Correlation between participant's age and percentage of the total Alzheimer's knowledge score; $r=0.099, p=0.004$

The highest known subscale of Alzheimer's disease in the present survey was assessment, followed by treatment, care giving, and course of the disease, whereas the lowest known subscale was symptoms. Different findings were observed in other studies. In China [19], defect knowledge was reported regarding life impact, symptoms, and care giving. Among older Chinese Americans, the lowest knowledge was observed regarding risk factors and symptoms [20]. In Malaysia, symptoms, course of the disease and life impacts were the lowest known items [15]. Comparison between these studies and the present one is not practical despite using the same study tool, due to difference in sociodemographic characteristics of the participants in various studies, including age, educational level, and occupation.

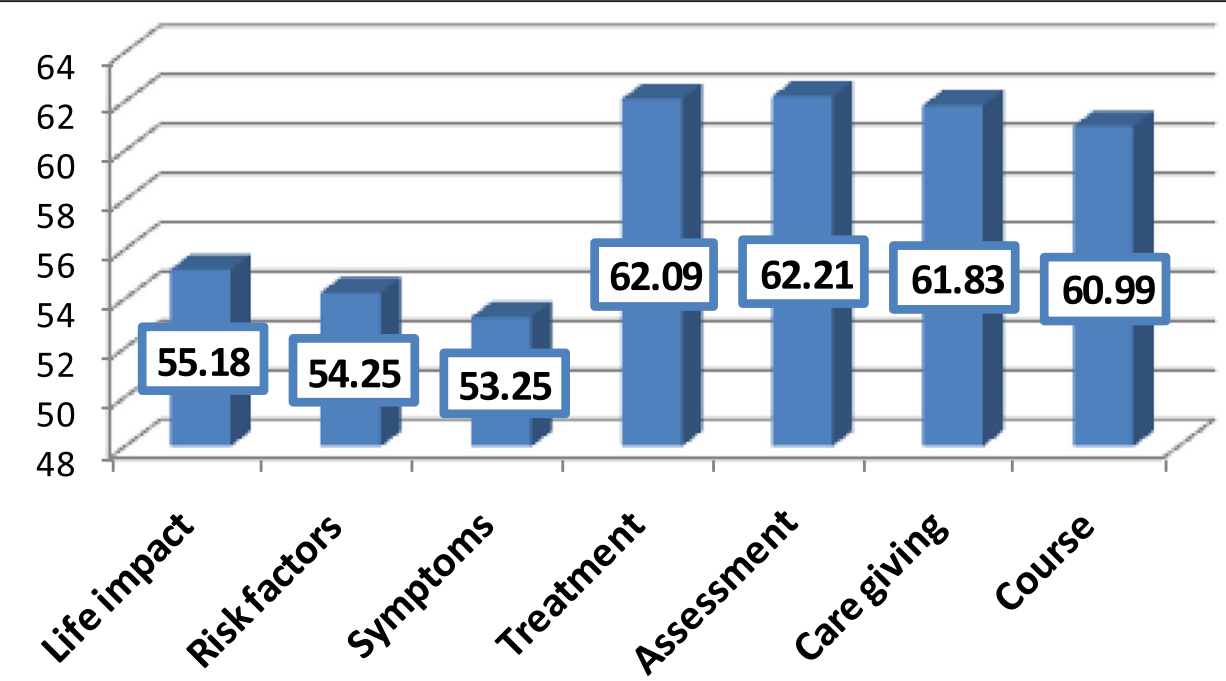

Fig. 4 Mean percentage of knowledge of different subscales of Alzheimer's disease 
Table 4 Knowledge of different aspects of Alzheimer's disease according to participant's gender

\begin{tabular}{|c|c|c|}
\hline & \multicolumn{2}{|l|}{ Gender } \\
\hline & Male & Female \\
\hline \multicolumn{3}{|c|}{ Life impact (\%) } \\
\hline Median & 66.67 & 66.67 \\
\hline IQR & $33.33-66.67$ & $33.33-66.67$ \\
\hline Mean rank & 435.09 & 428.63 \\
\hline$p$ value & 0.687 & \\
\hline \multicolumn{3}{|c|}{ Risk factors (\%) } \\
\hline Median & 50 & 50 \\
\hline IQR & $33.33-66.67$ & $33.33-66.67$ \\
\hline Mean rank & 433.58 & 429.84 \\
\hline$p$ value & 0.822 & \\
\hline \multicolumn{3}{|c|}{ Symptoms (\%) } \\
\hline Median & 50 & 50 \\
\hline IQR & $25-75$ & $25-75$ \\
\hline Mean rank & 420.18 & 440.55 \\
\hline$p$ value & 0.214 & \\
\hline \multicolumn{3}{|c|}{ Treatment (\%) } \\
\hline Median & 75 & 75 \\
\hline IQR & $50-75$ & $50-75$ \\
\hline Mean rank & 426.26 & 435.69 \\
\hline$p$ value & 0.563 & \\
\hline \multicolumn{3}{|c|}{ Assessment (\%) } \\
\hline Median & 75 & 50 \\
\hline IQR & $50-75$ & $50-75$ \\
\hline Mean rank & 444.55 & 421.06 \\
\hline$p$ value & 0.149 & \\
\hline \multicolumn{3}{|c|}{ Care giving (\%) } \\
\hline Median & 60 & 60 \\
\hline IQR & $40-80$ & $40-80$ \\
\hline Mean rank & 436.12 & 427.80 \\
\hline$p$ value & 0.614 & \\
\hline \multicolumn{3}{|c|}{ Course of the disease (\%) } \\
\hline Median & 50 & 50 \\
\hline IQR & $50-75$ & $50-75$ \\
\hline Mean rank & 416.45 & 443.53 \\
\hline$p$ value & 0.094 & \\
\hline
\end{tabular}

Mann-Whitney test
Table 5 Knowledge of different aspects of Alzheimer's disease according to participant's nationality

\begin{tabular}{|c|c|c|}
\hline & \multicolumn{2}{|l|}{ Nationality } \\
\hline & Saudi & Non-Saudi \\
\hline \multicolumn{3}{|c|}{ Life impact (\%) } \\
\hline Median & 66.67 & 66.67 \\
\hline IQR & $33.33-66.67$ & $33.33-66.67$ \\
\hline Mean rank & 429.51 & 443.95 \\
\hline$p$ value & 0.532 & \\
\hline \multicolumn{3}{|c|}{ Risk factors (\%) } \\
\hline Median & 50 & 50 \\
\hline IQR & $33.33-66.67$ & $33.33-66.77$ \\
\hline Mean rank & 429.17 & 446.06 \\
\hline$p$ value & 0.482 & \\
\hline \multicolumn{3}{|c|}{ Symptoms (\%) } \\
\hline Median & 50 & 50 \\
\hline IQR & $25-75$ & $25-75$ \\
\hline Mean rank & 431.93 & 428.80 \\
\hline$p$ value & 0.894 & \\
\hline \multicolumn{3}{|l|}{ Treatment (\%) } \\
\hline Median & 75 & 75 \\
\hline IQR & $50-75$ & $50-75$ \\
\hline Mean rank & 426.57 & 462.26 \\
\hline$p$ value & 0.129 & \\
\hline \multicolumn{3}{|c|}{ Assessment (\%) } \\
\hline Median & 75 & 50 \\
\hline IQR & $50-75$ & $50-75$ \\
\hline Mean rank & 436.77 & 398.63 \\
\hline$p$ value & 0.104 & \\
\hline \multicolumn{3}{|c|}{ Care giving (\%) } \\
\hline Median & 60 & 60 \\
\hline IQR & $40-80$ & $40-80$ \\
\hline Mean rank & 432.96 & 422.39 \\
\hline$p$ value & 0.656 & \\
\hline \multicolumn{3}{|c|}{ Course of the disease (\%) } \\
\hline Median & 50 & 50 \\
\hline IQR & $50-75$ & $50-75$ \\
\hline Mean rank & 436.08 & 402.89 \\
\hline$p$ value & 0.155 & \\
\hline
\end{tabular}

Mann-Whitney test
The finding that participants from Taif city were more knowledgeable regarding life impact and treatment compared to those from Jeddah and Makkah cities, whereas participants from Jeddah city were more knowledgeable regarding risk factors, while those from Makkah city were more knowledgeable regarding caregiving, cannot be explained easily; however, religious culture in Makkah could explain the higher knowledge regarding caregiving. However, further in-depth analysis of the characteristics of population in different cities as well as the components of the educational programs regarding $\mathrm{AD}$ implemented in these cities is warranted. 
Table 6 Knowledge of different aspects of Alzheimer's disease according to participant's years of education

\begin{tabular}{|c|c|c|c|}
\hline Years of education & & & \\
\hline$\leq 9$ & $10-12$ & $13-16$ & $>16 e$ \\
\hline
\end{tabular}

\begin{tabular}{|c|c|c|c|c|}
\hline \multicolumn{5}{|c|}{ Life impact (\%) } \\
\hline \multicolumn{5}{|c|}{ Median $\quad 66.67$} \\
\hline IQR & $33.33-66.67$ & $33.33-66.67$ & $33.33-66.67$ & $33.33-66.67$ \\
\hline \multirow{2}{*}{$\begin{array}{l}\text { Mean rank } \\
p \text { value }\end{array}$} & 445.61 & 448.87 & 422.39 & 422.89 \\
\hline & \multicolumn{4}{|l|}{0.496} \\
\hline
\end{tabular}

Risk factors (\%)

$\begin{array}{lllll}\text { Median } & 66.67 & 50 & 50 & 50 \\ \text { IQR } & 33.33-66.67 & 33.33-66.67 & 33.33-66.67 & 33.33-66.67 \\ \text { Mean rank } & 452.92 & 424.08 & 433.37 & 424.95 \\ \text { value } & 0.851 & & & \end{array}$

Symptoms (\%)

$\begin{array}{lllll}\text { Median } & 50 & 50 & 50 & 50 \\ \text { IQR } & 25-75 & 25-75 & 25-75 & 50-75 \\ \text { Mean rank } & 440.47 & 429.56 & 428.17 & 452.34 \\ p \text { value } & 0.861 & & & \end{array}$

Treatment (\%)

$\begin{array}{lllll}\text { Median } & 75 & 75 & 50 & 75 \\ \text { IQR } & 50-75 & 50-75 & 50-75 & 50-75 \\ \text { Mean rank } & 446.06 & 436.62 & 422.23 & 463.78 \\ p \text { value } & 0.488 & & & \end{array}$

Assessment (\%)

$\begin{array}{lllll}\text { Median } & 75 & 75 & 50 & 50 \\ \text { IQR } & 50-75 & 50-75 & 50-75 & 50-75 \\ \text { Mean rank } & 55.70 & 448.28 & 425.19 & 397.48 \\ p \text { value } & 0.296 & & & \end{array}$

Care giving (\%)

$\begin{array}{lllll}\text { Median } & 60 & 60 & 60 & 60 \\ \text { IQR } & 40-80 & 40-80 & 40-80 & 40-80 \\ \text { Mean rank } & 472.66 & 431.84 & 424.23 & 443.22 \\ p \text { value } & 0.482 & & & \end{array}$

Course of the disease (\%)

\begin{tabular}{|c|c|c|c|c|}
\hline Median & 50 & 50 & 75 & 75 \\
\hline IQR & $50-75$ & $50-75$ & $50-75$ & $50-75$ \\
\hline Mean rank & 387.97 & 403.01 & 448.05 & 452.55 \\
\hline$p$ value & 0.035 & & & \\
\hline
\end{tabular}

Although this study has a public health importance as being the first of its king in our area in exploring knowledge of the general population about Alzheimer's disease, it has some important limitations that should be mentioned. Its cross-sectional design confirms only association and not causality between
Table 7 Knowledge of different aspects of Alzheimer's disease according to participant's city

\begin{tabular}{|c|c|c|c|}
\hline & \multicolumn{3}{|l|}{ City } \\
\hline & Makkah & Jeddah & Taif \\
\hline \multicolumn{4}{|c|}{ Life impact (\%) } \\
\hline Median & 33.33 & 66.67 & 66.67 \\
\hline IQR & $33.33-66.67$ & $33.33-66.67$ & $33.33-66.67$ \\
\hline Mean rank & 390 & 430.41 & 466.13 \\
\hline$p$ value & 0.001 & & \\
\hline
\end{tabular}

\section{Risk factors (\%)}

$\begin{array}{llll}\text { Median } & 50 & 50 & 50 \\ \text { IQR } & 41.67-66.67 & 41.67-66.67 & 33.33-66.67 \\ \text { Mean rank } & 445.46 & 457.30 & 394.66 \\ p \text { value } & 0.003 & & \end{array}$

\section{Symptoms (\%)}

$\begin{array}{llll}\text { Median } & 50 & 50 & 50 \\ \text { IQR } & 50-75 & 25-75 & 25-75 \\ \text { Mean rank } & 446.90 & 421.14 & 429.31 \\ p \text { value } & 0.442 & & \end{array}$

Treatment (\%)

$\begin{array}{llll}\text { Median } & 50 & 50 & 75 \\ \text { IQR } & 50-75 & 50-75 & 50-75 \\ \text { Mean rank } & 409.95 & 418.39 & 461.90 \\ p \text { value } & 0.018 & & \end{array}$

\section{Assessment (\%)}

$\begin{array}{llll}\text { Median } & 75 & 75 & 75 \\ \text { IQR } & 50-75 & 50-75 & 50-75 \\ \text { Mean rank } & 435.92 & 427.07 & 432.32 \\ p \text { value } & 0.906 & & \end{array}$

\section{Care giving (\%)}

$\begin{array}{llll}\text { Median } & 80 & 60 & 60 \\ \text { IQR } & 60-80 & 40-80 & 40-80 \\ \text { Mean rank } & 508.97 & 427.18 & 373.15 \\ p \text { value } & <0.001 & & \end{array}$

\begin{tabular}{llll}
\multicolumn{2}{l}{ Course of the disease (\%) } \\
Median & 50 & 50 & 75 \\
IQR & $50-75$ & $50-75$ & $50-75$ \\
Mean rank & 436.44 & 412.88 & 445.95 \\
$p$ value & 0.206 & & \\
\hline Kruskal-Wallis test & &
\end{tabular}

dependent and independent variables. Limited studies have been conducted among general population; therefore, comparison with other studies is not practical as most of them were carried out among medical professionals. 
Table 8 Knowledge of different aspects of Alzheimer's disease according to participant's history of having relative with Alzheimer's disease

\begin{tabular}{ll}
\hline Having relative with Alzheimer disease \\
\cline { 2 - 3 } Yes No \\
\hline
\end{tabular}

Life impact (\%)

$\begin{array}{lll}\text { Median } & 66.67 & 66.67 \\ \text { IQR } & 33.33-66.67 & 33.33-66.67 \\ \text { Mean rank } & 425.91 & 452.84 \\ p \text { value } & 0.171 & \end{array}$

Risk factors (\%)

$\begin{array}{lll}\text { Median } & 50 & 50 \\ \text { IQR } & 33.33-66.67 & 50-66.67 \\ \text { Mean rank } & 426.23 & 451.61 \\ p \text { value } & 0.214 & \end{array}$

\section{Symptoms (\%)}

\section{Median}

IQR

Mean rank

$p$ value

Treatment (\%)

Median

Mean rank

$p$ value

Assessment (\%)

$\begin{array}{ll}\text { Median } & 75 \\ \text { IQR } & 50-75 \\ \text { Mean rank } & 428.81 \\ P \text { value } & 0.516\end{array}$

\section{Care giving (\%)}

$$
\text { Median }
$$$$
\text { IQR }
$$

Mean rank

$$
40-80
$$

60

$p$ value

$$
432.34
$$

428.28

Course of the disease (\%)

\begin{tabular}{lll} 
Median & 50 & 75 \\
IQR & $50-75$ & $50-75$ \\
Mean rank & 426.66 & 449.95 \\
$p$ value & 0.240 & \\
\hline
\end{tabular}

Mann-Whitney test

\section{Conclusion}

In conclusion, knowledge of the general population in Makkah Region is deficient, particularly regarding symptoms, risk factors, and life impacts. Therefore, health education campaigns are required for the general public in this regard with participation of healthcare professionals.

\section{Acknowledgements}

We are thankful to the following students for helping us in collecting data:

- Muslaha Musleh Alhumaidi

- Asma Salem Almatrafi

- Nada Eidhah Algethami

- Raghad Sami Aljuaid

- Albatoul Fayez Althobaiti

- Waad Daifallah Alotaibi

- Bushra Ahmed Alqahtani

- Ebtehal Amer Altalhi

- Shahad Abdullah Albaiti

- Shahad Ahmad Alshenawy

- Seham Matar Alotaibi

- Amjaad Ibraheem Hawsaw

- Ahlam Muhammed Alharbi

- Rama Khaled Tayeb

\section{Authors' contributions}

Study conception and design: All authors. Acquisition of data: All authors. Analysis and interpretation of data: Dr. Muhammad Irfanullah Siddiqui and Dr. Faisal Salem Alhumaidi Drafting of manuscript: All authors. Critical revision and final approval: All authors. All authors read and approved the final manuscript.

\section{Funding}

No source of funding for the study.

\section{Availability of data and materials}

Data are available upon request. Please contact the corresponding author.

\section{Ethics approval and consent to participate}

Written consent was taken from all participants after explaining the details, benefits, and risks to them. The study was approved by the Ethics Committee of Faculty of Medicine, Umm Al-Qura University-Makkah (No. HAPO-02-K-012-2018-06-269) on 2 June 2018.

\section{Consent for publication}

Not applicable.

\section{Competing interests}

The authors declare that they have no competing interests.

\section{Author details}

'Umm Al-Qura University College of Medicine, Mecca, Saudi Arabia.

${ }^{2}$ Department of Community Medicine, Faculty of Medicine, Umm Al-Qura University, Mecca, Saudi Arabia.

Received: 23 March 2020 Accepted: 6 August 2020

Published online: 28 August 2020

\section{References}

1. Wilson R, Rochon E, Leonard C, Mihailidis A. Formal caregivers' perceptions of effective communication strategies while assisting residents with Alzheimer's disease during activities of daily living..

2. American Psychiatric Association. Neurocognitive disorders. Diagnostic and statistical manual of mental disorders, Fifth Edition. Washington, DC: Americal Psychiatric Association 2013;611-614.

3. arabia mohpkos. World Alzheimer's Day 2013 [Available from: https://www. moh.gov.sa/en/healthawareness/healthday/2013/pages/healthday-019.aspx.

4. El-Metwally A, Toivola P, Al-Rashidi M, Nooruddin S, Jawed M, AlKanhal R, et al. Epidemiology of Alzheimer's disease and dementia in Arab countries: a systematic review. Behav Neurol 2019 Article ID 3935943; 14 pages. https://doi.org/10.1155/2019/3935943.

5. Sosso FA, Nakamura O, Nakamura M. Epidemiology of Alzheimer's disease: comparison between Africa and South America. J Neurol Neurosci. 2017; 8(4):204. https://doi.org/10.21767/2171-6625.1000204.

6. Gale CL. Ten warning signs of Alzheimer's disease, 2013. Available at: https://www.alz.org/media/Documents/alzheimers-dementia-memory-lossalzheimers-10-warning-signs-b.pdf.

7. Ho SC, Chan A, Woo J, Chong P, Sham A. Impact of caregiving on health and quality of life: a comparative population-based study of caregivers for 
elderly persons and noncaregivers. J Gerontol A Biol Sci Med Sci. 2009;64(8): 873-9. https://doi.org/10.1093/gerona/glp034.

8. Pinquart M, Sörensen S. Differences between caregivers and noncaregivers in psychological health and physical health: a meta-analysis. Psychology and aging. 2003;18(2):250.

9. Hyman BT, Phelps CH, Beach TG, Bigio EH, Cairns NJ, Carrillo MC, et al. National Institute on Aging-Alzheimer's Association guidelines for the neuropathologic assessment of Alzheimer's disease. Alzheimer's \& Dementia. 2012;8(1):1-3. https://doi.org/10.1016/j.jalz.2011.10.007.

10. Prince M, Bryce R, Ferri C. World Alzheimer Report 2011: the benefits of early diagnosis and intervention. Published by Alzheimer's Disease International (ADI); 2011. Available at: https://www.alz.co.uk/research/ WorldAlzheimerReport2011.pdf.

11. Rimmer E, Wojciechowska M, Stave C, Sganga A, O'Connell B. Implications of the Facing Dementia Survey for the general population, patients and caregivers across Europe. Int J Clin Pract Suppl. 2005;59:17-24.

12. Carpenter BD, Balsis S, Otilingam PG, Hanson PK, Gatz M. The Alzheimer's Disease Knowledge Scale: development and psychometric properties. Gerontologist. 2009 Apr 1;49(2):236-47.

13. Spector A, Orrell M, Schepers A, Shanahan N. A systematic review of 'knowledge of dementia'outcome measures. Ageing Res Rev. 2012;11(1):6777 https://doi.org/10.1016/j.arr.2011.09.002.

14. Amado DK, Brucki SM. Knowledge about Alzheimer's disease in the Brazilian population. Arquivos de neuro-psiquiatria. 2018;76(11):775-82.

15. Nuri M, Huda T, Hong YH, Ming LC, Mohd Joffry S, Othman MF, Neoh CF. Knowledge on Alzheimer's disease among public hospitals and health clinics pharmacists in the State of Selangor, Malaysia. Front Pharmacol. 2017; 8:739 https://doi.org/10.3389/fphar.2017.00739.

16. Smyth W, Fielding E, Beattie E, Gardner A, Moyle W, Franklin S, Hines S, MacAndrew M. A survey-based study of knowledge of Alzheimer's disease among health care staff. BMC geriatrics. 2013;13(1):2 https://doi.org/10.1186/ 1471-2318-13-2.

17. Nordhus IH, Sivertsen B, Pallesen S. Knowledge about Alzheimer's disease among Norwegian psychologists: the Alzheimer's disease knowledge scale. Aging \& mental health. 2012;16(4):521-8. https://doi.org/10.1080/13607863. 2011.628973.

18. Cahill S, Pierce M, Werner P, Darley A, Bobersky A. A systematic review of the public's knowledge and understanding of Alzheimer's disease and dementia. Alzheimer Dis Assoc Disord 2015;29(3):255-275.. https://doi.org/10. 1097/ WAD.00000000000000102.

19. Wang Y, Xiao LD, Luo Y, Xiao SY, Whitehead C, Davies O. Community health professionals' dementia knowledge, attitudes and care approach: a crosssectional survey in Changsha, China. BMC Geriatr. 2018;18(1):122.

20. Sun F, Gao X, Shen H, Burnette D. Levels and correlates of knowledge about Alzheimer's disease among older Chinese Americans. J Cross Cult Gerontol. 2014;29(2):173-83.

\section{Publisher's Note}

Springer Nature remains neutral with regard to jurisdictional claims in published maps and institutional affiliations.

\section{Submit your manuscript to a SpringerOpen ${ }^{\circ}$ journal and benefit from:}

- Convenient online submission

- Rigorous peer review

- Open access: articles freely available online

- High visibility within the field

- Retaining the copyright to your article

Submit your next manuscript at $\boldsymbol{\nabla}$ springeropen.com 